\title{
Dyssynchrony in obese subjects without a history of cardiac disease using velocity vector imaging
}

\author{
Bhaskar Purushottam MD \\ Jefferson Medical College \\ Anoop C. Parameswaran MD, MPH \\ Jefferson Medical College \\ Vincent M. Figueredo MD \\ Jefferson Medical College
}

Follow this and additional works at: https://jdc.jefferson.edu/cardiologyfp

Part of the Cardiology Commons

Let us know how access to this document benefits you

\section{Recommended Citation}

Purushottam MD, Bhaskar; Parameswaran MD, MPH, Anoop C.; and Figueredo MD, Vincent M., "Dyssynchrony in obese subjects without a history of cardiac disease using velocity vector imaging" (2011). Division of Cardiology Faculty Papers. Paper 9.

https://jdc.jefferson.edu/cardiologyfp/9

This Article is brought to you for free and open access by the Jefferson Digital Commons. The Jefferson Digital Commons is a service of Thomas Jefferson University's Center for Teaching and Learning (CTL). The Commons is a showcase for Jefferson books and journals, peer-reviewed scholarly publications, unique historical collections from the University archives, and teaching tools. The Jefferson Digital Commons allows researchers and interested readers anywhere in the world to learn about and keep up to date with Jefferson scholarship. This article has been accepted for inclusion in Division of Cardiology Faculty Papers by an authorized administrator of the Jefferson Digital Commons. For more information, please contact: JeffersonDigitalCommons@jefferson.edu. 
As submitted to:

Journal of the American Society of Echocardiography

And later published as:

Dyssynchrony in Obese Subjects without a History of Cardiac Disease Using

Velocity Vector Imaging

Volume 24, Issue 1, January 2011, Pages 98-106

DOI: 10.1016/j.echo.2010.10.003

Bhaskar Purushottam MDa , Anoop C. Parameswaran MD, MPH'a Vincent M. Figueredo MD ${ }^{\mathrm{a}}$

(a) Einstein Institute for Heart and Vascular Health, Albert Einstein Medical Center and Jefferson Medical College, Philadelphia.

Running Title: Intra Left Ventricular Dyssynchrony in Obesity

Conflict of Interest: The authors have no conflicts of interest to report.

Key Words: Dyssynchrony, Obese, Velocity Vector Imaging

Corresponding Author: Vincent M. Figueredo, MD, FACC, FASE

Associate Professor of Medicine, Jefferson Medical College

Director, Cardiovascular Diseases Fellowship Programs

Albert Einstein Medical Center

5501 Old York Road, Levy 3, Philadelphia, PA 19141

$215-456-8819$

figueredov@einstein.edu 
Abstract

Aim: To examine the occurrence of intra-left ventricular (LV) dyssynchrony in obese versus non-obese subjects without known cardiac disease using velocity vector imaging (VVI).

Methods: One hundred ninety consecutive subjects with no known cardiac disease had their echocardiograms analyzed using VVI after excluding subjects with QRS duration $\geq 120 \mathrm{~ms}$ or LV ejection fraction $(\mathrm{LVEF})<55 \%$. Study subjects were divided into two groups based on body mass index (BMI): obese (BMI $\geq 30 \mathrm{~kg} / \mathrm{m} 2)$ and non-obese (BMI $<30 \mathrm{~kg} / \mathrm{m} 2)$.

$\underline{\text { Results: }}$ The final cohort included 136 subjects (74 were obese), 32\% female and mean age $55 \pm 16$ years. Occurrence of intra LV dyssynchrony was higher in the obese compared to non-obese group.

Conclusions: There was an increased prevalence of intra LV dyssynchrony in obese subjects, especially longitudinal and radial dyssynchrony. This dyssynchrony may signal a mechanism by which obesity predisposes to the development of heart failure. 
Obesity is a modern epidemic, with greater than 60 million adults affected in the United States alone. ${ }^{1}$ Obesity is an important risk factor for heart failure in both men and women. Increased body mass index (BMI) has been reported in $11 \%$ and $14 \%$ of heart failure cases in men and women, respectively ${ }^{2}$. Left ventricular hypertrophy and dilatation ${ }^{1,3-5}$, which are known precursors of heart failure ${ }^{6,7}$ are associated with obesity. Also, obesity is associated with altered LV remodeling, possibly due to increased hemodynamic load, neurohormonal activation and increased cytokine production ${ }^{8}$. Myocardial triglyceride content appears to increase progressively with body mass index ${ }^{9}$. Recent experimental investigations suggest cardiac steatosis (excessive accumulation of cytosolic triglycerides in the myocardial cells), increased myocardial fibrosis, lipoapoptosis, and the activation of certain cardiac genes may underlie obesity cardiomyopathy ${ }^{10,11}$. Recent studies using positron emission tomography found that in obese young women, insulin resistance and obesity are related to alterations in fatty acid metabolism, which could play a role in decreased cardiac performance ${ }^{11-15}$. Whatever these intricate and complex molecular mechanisms may be, evidence suggests that long standing obesity results in LV structural and functional alterations producing volume overload, eccentric LV hypertrophy, systolic and diastolic dysfunction and heart failure ${ }^{16}$.

Marfella and associates demonstrated a higher occurrence of interventricular dyssynchrony in obese subjects using 2-dimensional (2-D) echocardiography with Doppler ${ }^{17}$. To our knowledge there have been no studies thus far examining the incidence of intra LV dyssynchrony in obese subjects who do not have a history of significant cardiac disease.

Myocardial contraction and relaxation are complex processes involving longitudinal, circumferential, radial and tortional forces. Velocity vector imaging (VVI) is a novel technique that uses myocardial speckle tracking to assess myocardial mechanics from 2-D echocardiography ${ }^{18}$. VVI uses an algorithm that automatically tracks motion of the tissue/cavity border and motion of reference points (mitral annulus), displaying tissue motion, direction and velocity (Figure 1). Unlike tissue Doppler imaging (TDI), VVI measures velocities independent of transducer angle. Also, in a recent study, Lim et al., demonstrated that the accuracy of TDI in assessing LV wall regional motion is limited in dilated ventricles and probably affects LV dyssynchrony measurement ${ }^{19}$.

Our aim was to examine the prevalence of intra LV dyssynchrony in obese subjects who have no history of cardiac disease and compare them with non-obese controls using VVI. 


\section{Methods:}

Five hundred consecutive subjects who had their 2-D echocardiograms performed at Albert Einstein Medical Center, Philadelphia between November 2008 and March 2009 on an Acuson Sequoia C512 (Sequoia, Siemens Medical Solutons Inc., Mountain View, California ${ }^{20}$ ) were screened. 310 subjects were excluded with the following exclusion criteria: 1) history of coronary artery disease; 2) left ventricular ejection fraction $(\mathrm{LVEF})<55 \% ; 3)$ diastolic dysfunction greater than grade 1 (mitral early to late diastolic inflow peak velocity ratio $\geq 0.8$, deceleration time of the mitral inflow $\leq 200 \mathrm{~ms}$, isovolumetric relaxation time $\leq$ $60 \mathrm{~ms}$, pulmonary venous systolic to diastolic peak velocity ratio $<1$ and mitral early inflow to early diastolic annular septal tissue peak velocity ratio $\geq 9$ as listed in American Society of Echocardiography criteria ${ }^{21}$ ) ; 4) QRS duration $\geq 120 \mathrm{~ms} ; 5$ ) moderate or severe valvular heart disease (using Doppler echocardiographic parameters-central jet $\geq 4 \mathrm{~cm}^{2}$ or jet area $\geq 20 \%$ of left atrial area for mitral regurgitation, central jet width $\geq$ $25 \%$ or vena contracta $\geq 0.3 \mathrm{~cm}^{2}$ or pressure half time $\leq 500 \mathrm{~ms}$ for aortic regurgitation, central jet area $>5 \mathrm{~cm}$ or proximal isovelocity surface radius $>0.5 \mathrm{~cm}$ for tricuspid regurgitation, jet size by color Doppler $>10 \mathrm{~mm}$ for pulmonary regurgitation-for regurgitant lesions ${ }^{22}$; mean gradient $\geq 20 \mathrm{~mm}$ of $\mathrm{Hg}$ or aortic valve area of $<$ $1.5 \mathrm{~cm}^{2}$ or aortic jet velocity of $\geq 3 \mathrm{~m} / \mathrm{s}$ for aortic stenosis, mitral valve area $<1.5 \mathrm{~cm}^{2}$ or mean gradient of $\geq$ $5 \mathrm{~mm}$ of $\mathrm{Hg}$ for mitral stenosis, tricuspid valve area $<1 \mathrm{~cm}^{2}$ or mean gradient $\geq 5 \mathrm{~mm}$ of $\mathrm{Hg}$ or inflow timevelocity time integral $>60 \mathrm{~cm}$ or pressure half time $\geq 190 \mathrm{~ms}$ for tricuspid stenosis, peak velocity $\geq 3 \mathrm{~m} / \mathrm{s}$ or peak gradient $\geq 36 \mathrm{~mm}$ of $\mathrm{Hg}$ for pulmonic stenosis-for stenotic lesions ${ }^{23}$ ) ; 6) pacemaker; 7) hypertrophic cardiomyopathy; 8) pericardial effusion or disease; 9) poor quality images where the myocardium was not visible and; 10) any subject admitted to the intensive care unit. Subjects were divided into two groups based on body mass index (BMI): 1) BMI of greater than or equal to $30 \mathrm{~kg} / \mathrm{m} 2$ (obese) and 2) BMI less than 30 $\mathrm{kg} / \mathrm{m} 2$ (non-obese). We also compared morbidly obese subjects (BMI of greater than or equal to $40 \mathrm{~kg} / \mathrm{m}^{2}$ ) to obese subjects $(\mathrm{BMI} \geq 30$ to $<40)$.

VVI was performed using the Acuson Sequoia C512. Images were captured using frame rates used for traditional 2-D echocardiograms (30-60 frames/sec.). VVI uses a series of tracking algorithms whose details are described elsewhere ${ }^{18}$. In brief, the endocardial-myocardial interface is traced manually in a single frame on a digital cine-loop. When the image is processed, a complex algorithm tracks each pixel and the myocardial velocity vectors are displayed in cine format. The lengths of the vectors are proportional to the magnitude of velocity and the direction of the arrows corresponds to the direction of myocardial motion. One cardiac cycle was analyzed if the RR intervals were regular, and an average of 3 beats was used if RR intervals were irregular. Apical four chamber, two chamber and short axis views at the papillary muscle level 
were studied off-line. In the apical four and two chamber views, a trace was made (along the endocardialmyocardial interface) from the septal to lateral mitral annulus and from the inferior to anterior mitral annulus respectively. In the short axis view at the level of papillary muscles, a circumferential trace was made starting at 12 o'clock position and ending at the same point in a clockwise direction, excluding the papillary muscles. Approximately one point per myocardial segment was used to draw the trace. A point of reference was placed at the apex in the two and four chamber views to calculate longitudinal velocities and strain. The point of reference was moved to the left ventricular cavity to calculate radial velocities. In the short axis view, the point of reference was at the center of the left ventricle to calculate circumferential velocities and strain. Longitudinal velocity, longitudinal strain and radial velocities were measured at the basal septal, basal lateral, basal anterior and basal inferior walls in the apical four and two chamber views. The circumferential velocities and strain were measured in the short axis view at the papillary muscle level. Time to peak velocities and strain were calculated from the onset of the QRS complex to the peak systolic velocity or peak strain respectively during the ejection phase. We defined mechanical dyssynchrony as longitudinal opposing wall delay $>75 \mathrm{~ms}$ by VVI based on a prior $\mathrm{study}^{24}$. As there are no published criteria for circumferential dyssynchrony and since we were looking at the maximum delay between all 6 segments in the short axis view, not just the opposing wall delays, we used a higher number (maximum delay $\geq 100 \mathrm{~ms}$ ) to define circumferential dyssynchrony. We used a value of $75 \mathrm{~ms}$ for septal to lateral wall radial delay. An example of longitudinal and circumferential LV dyssynchrony analysis using the above mentioned VVI technique is illustrated in figures 2 and 3, respectively.

Patient demographics, clinical characteristics, hemodynamic measurements, laboratory data, echocardiographic parameters and electrocardiographic data were collected (Tables 1 and 2). Patient demographics collected were age, gender and race. Clinical characteristics collected were any history of hypertension (blood pressure $\geq 140 / 90 \mathrm{~mm}$ of $\mathrm{Hg}$ as defined by the $7^{\text {th }}$ report of the 'Joint National Committee on Prevention, Detection, Evaluation and Treatment of High Blood Pressure ${ }^{, 25}$ or if they are on anti-hypertensives), diabetes mellitus (fasting plasma glucose $\geq 126 \mathrm{mg} / \mathrm{dl}$ as per the 'American Diabetes Association ${ }^{26}$ or if they are on anti-diabetes treatment), prior history of transient ischemic attack ${ }^{27}$, ischemic stroke $^{28}$ or intracranial hemorrhage, hypercholesterolemia (low density lipoprotein levels $\geq 130 \mathrm{mg} / \mathrm{dl}$ as per 'National Cholesterol Education Program' report ${ }^{29}$ or if they are on a HMG CoA reductase inhibitor), a diagnosis of obstructive sleep apnea ${ }^{30}$, a diagnosis of stable chronic obstructive pulmonary disease ${ }^{31}$ and whether the subjects were on hemodialysis. Hemodynamic measurements recorded were heart rate and systolic and diastolic blood pressure recorded immediately prior to performing the echocardiogram. Laboratory data obtained were hemoglobin and creatinine, which were done closest to the time of the echocardiogram. QRS duration was recorded from the electrocardiogram. All echocardiographic 
measurements were based on ASE guidelines. Left ventricular diastolic dimension (LVIDd), septal wall thickness (SWT), posterior wall thickness (PWT), left atrial diameter and LV mass were measured using 2Dguided M-mode, assuming that the $\mathrm{LV}$ is a prolate ellipse in the parasternal long-axis acoustic window ${ }^{32}$. LV mass was indexed to body surface area. Diastolic dysfunction and the grade of dysfunction ${ }^{21}$, LVEF (was calculated using the modified Simpson's rule ${ }^{32}$ ) and pulmonary artery systolic pressures ${ }^{33}$ were measured.

The study was approved by the institutional research board of Albert Einstein Medical Center, Philadelphia. 
Statistical Analysis:

Data were analyzed using the SPSS 10 (Chicago, IL, USA). Continuous data are presented as mean \pm SD. Means were compared using a two-tailed student $t$ test. Multivariate analysis was performed using the regression model. Chi-square test was used to compare categorical variables. A p value less than 0.05 were considered significant. Co-efficient of variation (COV) was used to measure the inter and intra-observer variability on 20 random obese and non-obese subjects. 
$\underline{\text { Results: }}$

The final cohort consisted of 136 subjects. Thirty subjects were excluded from the obese group and 24 from the non-obese group. Among the 30 excluded obese subjects, 17 were excluded due to incomplete data and 13 due to poor quality echocardiograms. Among the 24 excluded non-obese subjects, 15 were excluded due to incomplete data and 9 due to poor quality echocardiograms. In the final cohort, 74 were obese subjects and 62 were non-obese controls. Mean age was $55 \pm 16$ years, $32 \%$ were female, mean QRS duration was 84 $\pm 9 \mathrm{~ms}$ and mean $\mathrm{LVEF}$ was $60 \pm 8 \%$. Of note, no subject had a $\mathrm{LVEF}<55 \%$, while others were more hyperdynamic. Demographic and clinical data were well matched between the two groups (Table 1). Echocardiographic, hemodynamic and electrocardiographic parameters are reported in Table 2. Among the 72 obese subjects, 50 (68\%) had a BMI between 30 to 40 and 24 (32\%) had a BMI $\geq 40$ (morbidly obese). The inter and intra-observer variability was calculated for all the different VVI measurements done in the study for the 20 random obese and non-obese subjects. The COV for longitudinal, radial and circumferential time to peak velocities were $5 \%, 6 \%$ and $6 \%$, respectively for inter-observer variability; $5 \%, 5 \%$ and $6 \%$, respectively for intra-observer variability. The COV for longitudinal and circumferential strain were $8 \%$ and $8 \%$, respectively for inter-observer variability; $7 \%$ and $8 \%$, respectively for intra-observer variability.

\section{$\underline{\text { Velocity Vector Analysis (Table 3) }}$}

\section{a) Longitudinal velocity}

Among the obese subjects, $9.4 \%(n=7)$ had a longitudinal septal to lateral (S-L) wall time to peak delay of $>75 \mathrm{~ms}$ whereas, $0 \%$ of the non-obese subjects had evidence of dyssynchrony $(\mathrm{p}=0.01)$. There were no significant differences in the longitudinal absolute peak velocities of the basal myocardial walls (measured in the apical 2 chamber and 4 chamber views) between the two groups (obese and non-obese).

b) Radial velocity

Among the obese subjects, $31.0 \%(n=23)$ had a radial septal to lateral (S-L) wall time to peak delay of $>75 \mathrm{~ms}$ as compared to $8.0 \%(\mathrm{n}=5)$ among non-obese subjects $(\mathrm{p}<0.01)$. There were no significant differences in the radial absolute peak velocities of the basal myocardial walls (measured in the apical 2 chamber and 4 chamber views) between the two groups.

\section{c) Circumferential velocity}

Among the obese subjects, $27.0 \%(n=20)$ had a maximum opposing wall time to peak circumferential delay of $>100 \mathrm{~ms}$ compared to $1.6 \%(\mathrm{n}=1)$ among non-obese subjects $(\mathrm{p}<0.01)$. There were no significant differences in the circumferential absolute peak velocities between the obese and non-obese subjects. 
a) Longitudinal Strain

Among the obese subjects, $58.1 \%(n=43)$ had a maximum opposing wall time to peak delay in longitudinal strain of $>100 \mathrm{~ms}$ compared to $33.8 \%(\mathrm{n}=21)$ among non-obese subjects $(\mathrm{p}<0.01)$. There were no significant differences in the longitudinal strain between the two groups.

b) Circumferential Strain

Among the obese subjects, $10.8 \%(n=8)$ had a maximum opposing wall time to peak delay in circumferential strain of $>100 \mathrm{~ms}$ as compared to $1.6 \%(\mathrm{n}=1)$ among non-obese subjects $(\mathrm{p}=0.03)$. There were no significant differences in circumferential peak strain between the obese and non-obese subjects.

\section{Comparison Between Obese and Non-Obese Groups}

There was significantly increased time to peak delay in longitudinal, radial and circumferential velocities and delay in time to peak longitudinal and circumferential strain in obese subjects when compared to nonobese subjects (Table 4). Obese subjects had a higher LVIDd, LV mass, QRS duration, systolic and diastolic blood pressures (but all still within normal reference limits), when compared to the non-obese subjects. Even after adjusting for these confounding variables, in addition to age, race, gender, LV mass index and LVEF, the obese subjects had a significantly increased LV dyssynchrony when compared to the non-obese subjects on a multivariate analysis (Table 5).

\section{Comparison of Dyssynchrony between Obese and Morbidly Obese groups (Table 6)}

There were no significant differences in longitudinal, radial and circumferential time to peak velocities and time to peak longitudinal and circumferential strain or myocardial peak velocities and peak strain between obese and morbidly obese subjects.

\section{Comparison of LVEF between obese subjects with and without dyssynchrony (Figure 4)}

Obese subjects with time to peak delay in longitudinal septal to lateral wall velocity of $>75 \mathrm{~ms}$ had a lower LVEF $(55 \pm 0 \%)$ when compared to obese subjects with time to peak longitudinal S-L wall delay of $\leq 75 \mathrm{~ms}$ $(60 \pm 7 \% ; \mathrm{p}<0.01)$. Obese subjects with time to peak delay in radial $\mathrm{S}-\mathrm{L}$ wall velocity $>75 \mathrm{~ms}$, delay in time to peak circumferential velocity $>100 \mathrm{~ms}$ or delay in time to peak longitudinal and circumferential strain had similar LVEF when compared to non-obese subjects.

\section{Comparison of LVEF between obese and non-obese subjects with dyssynchrony}

The LVEF was lower in the obese group when compared to the non-obese group among the subjects with a longitudinal strain maximum opposing wall delay $>100 \mathrm{~ms}(59 \pm 6 \%$ vs. $62 \mathrm{~ms} \pm 8 \%$; $>0.05)$, radial septallateral wall delay $>75 \mathrm{~ms}(59 \pm 7 \%$ vs. $63 \pm 9 \% ; \mathrm{p}>0.05)$ and radial maximum opposing wall delay $>100 \mathrm{~ms}$ 
$(60 \pm 7 \%$ vs. $61 \pm 9 \% ; p>0.05)$. There were very few non-obese subjects with longitudinal, circumferential and circumferential strain dyssynchrony (table 3.) to make a statistically appropriate comparison.

\section{Subjects with QRS duration $>100 \mathrm{~ms}$}

Seven study subjects had QRS duration >100ms; six were obese. When comparing dyssynchrony between subjects with QRS duration $>100 \mathrm{~ms}$ and those with QRS duration $\leq 100 \mathrm{~ms}$, only longitudinal strain septallateral wall delay was increased $(86.43 \pm 39.97 \mathrm{~ms}$ vs. $48.56 \pm 72.14 \mathrm{~ms} ; \mathrm{p}<0.05)$. 
Discussion:

Multiple parameters of intra LV dyssynchrony, including radial and longitudinal dyssynchrony, were more frequent in obese subjects when compared to non-obese subjects. After multivariate analysis, obesity remained a significant independent predictor of intra LV dyssynchrony. Interestingly, there were no significant differences in the peak myocardial velocities or peak myocardial strain between obese and nonobese subjects.

Obesity is associated with left ventricular hypertrophy and dilatation ${ }^{1,3-5}$ known precursors of heart failure $^{6,}$ ${ }^{7}$. Obesity is associated with altered LV remodeling, possibly due to increased hemodynamic load, neurohormonal activation and increased cytokine production ${ }^{8}$. There is very little data examining ventricular dyssynchrony in obese subjects. One study by Marfella et al., in 2004 described interventricular dyssynchrony among premenopausal obese women, which improved significantly after a $10 \%$ weight $\operatorname{loss}^{17}$. They used pulmonary vein flow analysis, E/A ratios (ratio of mitral early and late diastolic flow velocities) and myocardial performance index $(\mathrm{MPI}=$ [isovolumetric relaxation time + isovolumetric contraction time]/left ventricular ejection time) to assess interventricular dyssynchrony. Tumuklu et al., suggested that decreased regional strain rate seen in obese, compared to the non-obese subjects, was a reflection of subclinical changes in LV systolic function ${ }^{34}$. However, they did not study dyssynchrony between these two groups.

Ten Harkel et al., investigated intra LV dyssynchrony and LV volumes in 73 healthy adolescents (age range of $12-18$ years) using real-time three-dimensional echocardiography ${ }^{35}$. In contrast to the present study, they found dyssynchrony values were independent of weight, length and body surface area. However, there were significant differences in these study populations. In the present study, subjects were older than the adolescents (55 versus 15 years old). Further, Ten Harkel et al., did not report the proportion of adolescents who were overweight or obese, therefore making it difficult to assess the association of obesity and intra LV dyssynchrony. On similar lines, $\mathrm{Ng}$ and et al., prospectively investigated the impact of age, gender and other physiological parameters on LV longitudinal and radial synchrony using TDI and 2-dimensional speckle tracking and found that dyssynchrony was independent of $\mathrm{BMI}^{36}$. The mean BMI of the study group was $25.8 \pm 4.9$, and the proportion of obese subjects was not reported. Therefore, it is difficult to arrive at any conclusions with regards to obesity and LV dyssynchrony based on these prior studies.

Bernheim et al., found that patients with normal, clinically indicated exercise echocardiograms (LVEF $>50 \%$ ) and QRS duration $<120 \mathrm{~ms}$, who had abnormal dyssynchrony parameters at rest had a higher resting 
heart rate and achieved a lower workload ${ }^{37}$. They felt that this indicated early myocardial impairment. Chang et al., found that LV systolic and diastolic dyssynchrony in asymptomatic patients with hypertension who had a QRS duration $<120 \mathrm{~ms}$ and normal range LVEF were significantly associated with LV filling pressure $^{38}$. In view of the above studies and with the results of our study, intra LV dyssynchrony may play a role in the mechanisms underlying heart failure development in obese subjects.

Myocardial triglyceride content appears to increase progressively with body mass index ${ }^{9}$. Experimental investigations suggest that this cardiac steatosis (excessive accumulation of cytosolic triglycerides in the myocardial cells), increases myocardial fibrosis and lipoapotosis and may underlie obesity cardiomyopathy $^{10,11}$. Rijzewijk et al., demonstrated that myocardial steatosis is an independent predictor of diastolic dysfunction in patients with type 2 diabetes mellitus ${ }^{39}$ and Kankaanpää et al., showed that the free fatty acid levels were significantly correlated with LV mass ${ }^{40}$. These studies applied magnetic resonance imaging and spectroscopy techniques to quantify myocardial triglyceride content. However, quantification of regional differences of triglyceride content in the myocardium is difficult as the heart is perpetually in motion and is surrounded by a large depot of adipocytes (epicardial fat pad) that interferes with measurements ${ }^{41}$. Thus, whether regional variations in myocardial steatosis exist and plays a role in the observed dyssynchrony in obese patients requires further study. Of note, the obese subjects in the present study had an increased LV mass, LVIDd, PWT, blood pressure, and QRS duration when compared to the non-obese subjects. However, these confounding variables did not influence our results after multivariate analysis (Table 4).

As mentioned earlier, we found no differences in the peak velocities and strain achieved by the different myocardial walls between obese and non-obese subjects. Contrary to our study, Tumuklu et al., using reconstructed spectral pulsed wave tissue Doppler showed significantly decreased myocardial peak velocities, regional and global strain among obese subjects when compared to non-obese controls ${ }^{34}$. The present study was cross-sectional so that we could not test the possibility of dyssynchrony preceding changes in peak velocities and strain. Further, dyssynchrony looks at the difference in the time taken to achieve peak velocities or strain between opposing walls and not at the absolute velocities or strain and changes in these different parameters need not simultaneously occur.

Contrary to the existing literature, there were fewer obese subjects in our study with obstructive sleep apnea and elevated pulmonary artery pressures. This could be explained by the fact that our study was retrospective and many of our subjects had not yet had a sleep study. Thus the reported number of subjects with obstructive sleep apnea is observational in this population. It is likely that the number of obese subjects with 
obstructive sleep apnea is underestimated. Given the fact that we excluded subjects who had moderate or severe tricuspid regurgitation, low LVEF, diastolic dysfunction greater than grade 1 or those who were admitted to the intensive care unit, several obese subjects with elevated pulmonary artery pressures were excluded.

Our study raises multiple questions and possibilities regarding the occurrence of dyssynchrony in obese subjects and its role in the causation of systolic dysfunction in obese subjects. With obesity being a rising worldwide epidemic, and with its harmful effects on cardiac function, and contribution to heart failure, further studies are warranted. It would also be interesting to see if obese individuals are better cardiac resynchronization therapy responders than their non-obese counterparts, as we see an increased occurrence of dyssynchrony among obese subjects. 
Limitations:

This is a retrospective study limited to an inner city single medical center. Since a lower frame rate was used for VVI, it is conceivable that some very rapid velocities may not be recorded. Nevertheless, comparison between the time to peak velocities between two walls should remain valid. Some MRI studies looking at the heterogeneity in LV contraction used frame rates ranging from $14-35 \mathrm{~ms}$. This is comparable with the 30-60 f/s (16 - $33 \mathrm{~ms})$ used in this study. Unlike speckle tracking echocardiography, which can measure radial strain in the short axis views ${ }^{42}$, VVI cannot measure these radial velocities in the short axis view and LV torsion that could have given us more information about LV function. Waist to hip ratio was not calculated as these were not standard measurements for subjects who underwent echocardiography. Waist to hip ratio is a stronger correlate of LV dysfunction and mortality when compared to $\mathrm{BMI}^{43}$. As this was a retrospective study, we could not accurately estimate the duration of obesity for each subject and therefore assess its effect on dyssynchrony. As this was not a longitudinal study and clinical effects were not measured, these findings should be viewed as thought provoking with future studies assessing the potential contribution of intra LV dyssynchrony in obese subjects with clinical endpoints such as heart failure. 
Conclusions:

There was increased intra LV dyssynchrony among obese subjects when compared to non-obese subjects, especially longitudinal and radial dyssynchrony. This dyssynchrony may signal one mechanism by which obesity predisposes to the development of heart failure. 


\section{$\underline{\text { References: }}$}

1. American Obesity Association. AOA fact sheets: "Obesity in the U.S."Available at http://www.obesity.org/subs/fastfacts/obesity_US.shtml. Accessed February 2004.

2. Kenchaiah S, Evans JC, Levy D, Wilson PW, Benjamin EJ, Larson MG, et al. Obesity and the risk of heart failure. N Engl J Med 2002; 347:305-13

3. Messerli FH, Sundgaard-Riise K, Reisin ED, Dreslinski GR, Ventura HO, Oigman W, et al. Dimorphic cardiac adaptation to obesity and arterial hypertension. Ann Intern Med 1983; 99:757-61.

4. Ogden CL, Carroll MD, McDowell MA, Flegal KM. Obesity among adults in the United States - no change since 2003-2004. NCHS data brief no 1. Hyattsville, MD. National Center for Health Statistics, 2007.

5. Alpert MA, Lambert CR, Terry BE, Cohen MV, Mukerji V, Massey CV, et al. Influence of left ventricular mass on left ventricular diastolic filling in normotensive morbid obesity. Am Heart J 1995; 130:1068-73. 6. Vasan RS, Larson MG, Benjamin EJ, Evans JC, Levy D. Left ventricular dilatation and the risk of congestive heart failure in people without myocardial infarction. N Engl J Med 1997; 336:1350-5.

\section{Gardin JM, McClelland R, Kitzman D, Lima JA, Bommer W, Klopfenstein HS,et al. M-mode}

Echocardiographic predictors of six- to seven-year incidence of coronary heart disease, stroke, congestive heart failure, and mortality in an elderly cohort (the Cardiovascular Health Study). Am J Cardiol 2001; $87: 1051-7$

8. Kopelman PG. Obesity as medical problem. Nature 2000; 404:635-43

9. Szczepaniak LS, Dobbins RL, Metzger GJ, Sartoni-D’Ambrosia G, Arbique D, Vongpatanasin W, et al. Myocardial triglycerides and systolic function in human: in vivo evaluation by localized proton spectroscopy and cardiac imaging. Magn Reson Med. 2003; 49:417-23

10. Cittadini A, Mantzoros CS, Hampton TG, Travers EK, Katz SE, Morgan PJ, et al. Cardiovascular alterations in transgenic mice with reduced brown fat: an animal model of human obesity. Circulation 1999; 100:2177-83. 
11. Chiu HC, Kovacs A, Ford DA, Hsu FF, Garcia R, Herrero P, et al. A novel mouse model of lipotoxic cardiomyopathy. J Clin Invest 2001; 107:813-822

12. Peterson LR, Herrero P, Schechtmann KB, Racette SB, Waggoner AD, Kisrieva-Ware Z, et al. Effect of obesity and insulin resistance on myocardial substrate metabolism and efficiency in young women. Circulation 2004; 109:2191-2196

13. Marwick TH, Wong CY. Role of exercise and metabolism in heart failure with normal ejection fraction. Prog Cardiovasc Dis 2007; 49:263-274.

14. Peterson LR, Waggoner AD, Schechtmen KB, Meyer T, Gropler RJ, Barzilai B, et al. Alterations in left ventricular structure and function in young healthy obese women. J Am Coll Cardiol 2004; 43:1399 -1404.

15. Di Bello V, Santini F, Di Cori A, Pucci A, Palagi C, Delle Donne MG, et al. Obesity cardiomyopathy:is it a reality? An ultrasonic tissue characterization study. J Am Soc Echocardiogr 2006; 19:1063-1071.

16. Flegal KM, Carrol MD, Ogden CL, Johnson CL. Prevalence and trends in obesity among US adults, 1999-2000. JAMA 2002; 288:1772-3.

17. Marfella R, Esposito K, Siniscalchi M, Cacciapuoti F, Giugliano F, Labriola D, et al. Effect of Weight Loss on Cardiac Synchronization and Proinflammatory Cytokines in Premenopausal Obese Women. Diabetes Care 2004; 27:47-52

18. www.medical.siemens.com/siemens/en_US/gg_us_FBAs/files/misc_downloads/ Whitepaper_Jackson.pdf

19. Lim P, Mitchell-Heggs L, Buakhamsri A, Thomas JD, Grimm RA. Impact of left ventricular size on tissue Doppler and longitudinal strain by speckle tracking for assessing wall motion and mechanical dyssynchrony in candidates for cardiac resynchronization therapy. J Am Soc Echocardiogr 2009;22:695-701.

20. www.medical.siemens.com/webapp/wcs/stores/servlet/ProductDisplay q_catalogId e_-

1 a_catTree e_100010,1007660,12761,1003854 a_langId e_-

1 a_productId e_137961 a_storeId e_10001.htm 
21. Nagueh SF, Appleton CP, Gillebert CT, Marino PN, Oh JK, Smiseth OA, et al; Recommendations for the evaluation of left ventricular diastolic function by echocardiography. J Am Soc Echocardiogr 2009; 22(2):107-33.

22. Baumgartner H, Hung J, Bermejo J, Chambers JB, Evangelista A, Griffin BP, et al. Echocardiographic assessment of valve stenosis: EAE/ASE recommendations for clinical practice.American Society of Echocardiography; European Association of Echocardiography. J Am Soc Echocardiogr 2009; 22(1):1-23

23. Zoghbi WA, Enriquez-Sarano M, Foster E, Grayburn PA, Kraft CD, Levine RA, et al. Recommendations for evaluation of the severity of native valvular regurgitation with two-dimensional and Doppler echocardiography. J Am Soc Echocardiogr. 2003; 16(7):777-802.

24. Cannesson M, Tanabe M, Suffoletto MS, Schwartzman D, Gorcsan J, 3rd. Velocity vector imaging to quantify ventricular dyssynchrony and predict response to cardiac resynchronization therapy. Am J Cardiol 2006; 98:949-53.

25. Chobanian AV, Bakris GL, Black HR, Cushman WC, Green LA, Izzo JL Jr, et al. The JNC 7 report. JAMA 2003; 289(19):2560-72

26. Position Statement. Standards of medical care in diabetes--2010. American Diabetes Association. Diabetes Care. 2010 Jan;33 Suppl 1:S11-61.

27. Easton JD, Saver JL, Albers GW, Alberts MJ, Chaturvedi S, Feldmann E, et al. Definition and Evaluation of Transient Ischemic Attack: A Scientific Statement for Healthcare Professionals From the American Heart Association/American Stroke Association Stroke Council; Council on Cardiovascular Surgery and Anesthesia; Council on Cardiovascular Radiology and Intervention; Council on Cardiovascular Nursing; and the Interdisciplinary Council on Peripheral Vascular Disease. Stroke. 2009;40:2276-2293

28. van der Worp HB, van Gijn J. Clinical practice. Acute ischemic stroke. N Engl J Med 2007;357:572-9.

29. Third report of the expert panel on detection, evaluation, and treatment of the high blood cholesterol in adults (Adult Treatment Panel III final report). http://www.nhlbi.nih.gov/guidelines/cholesterol/atp3full.pdf 
30. Patil SP, Schneider H, Schwartz A, Smith P. Adult obstructive sleep apnea: pathophysiology and diagnosis. Chest. 2007; 132:325-37

31. Qaseem A, Snow V, Shekelle P, Sherif K, Wilt TJ, Weinberger S, et al. Clinical Efficacy Assessment Subcommittee of the American College of Physicians. Diagnosis and management of stable chronic obstructive pulmonary disease: a clinical practice guideline from the American College of Physicians. Ann Intern Med. 2007; 147:633-8.

32. Lang RM, Bierig M, Devereux RB, Flachskampf FA, Foster E, Pellikka PA, et al. Chamber Quantification Writing Group; American Society of Echocardiography's Guidelines and Standards Committee; European Association of Echocardiography. Recommendations for chamber quantification: a report from the American Society of Echocardiography's Guidelines and Standards Committee and the Chamber Quantification Writing Group, developed in conjunction with the European Association of Echocardiography, a branch of the European Society of Cardiology. J Am Soc Echocardiogr 2005;18:14401463.

33. Rudski LG, Lai WW, Afilalo J, Hua L, Handschumacher M, Chandrasekaran K, et al. Guidelines for the Echocardiographic Assessment of the Right Heart in Adults: A Report from the American Society of Echocardiography. Endorsed by the European Association of Echocardiography, a registered branch of the European Society of Cardiology, and the Canadian Society of Echocardiography. J Am Soc Echocardiogr 2010;23:685-713

34. Tumuklu MM, Etikan I, Kisacik B, Kayikcioglu M. Effect of obesity on left ventricular structure and myocardial systolic function: assessment by tissue Doppler imaging and strain/strain rate imaging. Echocardiography. 2007; 24:802-9.

35. Ten Harkel AD, Van Osch-Gevers M, Helbing WA. Real-time transthoracic three dimensional echocardiography: normal reference data for left ventricular dyssynchrony in adolescents. J Am Soc Echocardiogr 2009;22:933-38.

36. Ng AC, Tran DT, Newman M, Allman C, Vidaic J, Lo ST et al. Left ventricular longitudinal and radial synchrony and their determinants in healthy subjects. J Am Soc Echocardiogr 2008;21:1042-48. 
37. Bernheim AM, Nakajima Y, Pellikka PA. Left ventricular dyssynchrony in patients with normal ventricular systolic function referred for exercise echocardiography. J Am Soc Echocardiogr 2008;21:114549.

38. Chang SA, Kim HK, Kim DH, Kim YJ, Sohn DW, Oh BH et al. Left ventricular systolic and diastolic dyssynchrony in asymptomatic hypertensive patients. J Am Soc Echocardiogr 2009;22:337-42

39. Rijzewijk LJ, Van der Meer RW, Smit JW, Diamant M, Bax JJ, Hammer S, et al. Myocardial steatosis is an independent predictor of diastolic dysfunction in type 2 diabetes mellitus. J Am Coll Cardiol 2008; 52:1793-9.

40. Kankaanpää M, Lehto HR, Pärkkä JP, Komu M, Viljanen A, Ferrannini E, et al. Myocardial Triglyceride Content and Epicardial Fat Mass in Human Obesity: Relationship to Left Ventricular Function and Serum Free Fatty Acid Levels. J Clin Endocrinol Metab 2006; 91:4689-4695.

41. McGavock JM, Victor RG, Unger RH, Szczepaniak LS. Adiposity of the heart*, Revisited. Ann Intern Med. 2006; 144:517-524.

42. Gorcsan J, III, Abraham T, Agler DA, Bax JJ, Derumeaux G, Grimm RA et al. Echocardiography for cardiac resynchronization therapy: recommendations for performance and reporting--a report from the American Society of Echocardiography Dyssynchrony Writing Group endorsed by the Heart Rhythm Society. J Am Soc Echocardiogr 2008;21:191-213.

43. Ammar KA, Redfield MM, Mahoney DW, Johnson M, Jacobsen SJ, Rodeheffer RJ. Central obesity: association with left ventricular dysfunction and mortality in the community. Am Heart J 2008; 156:975-81. 
Figure legends:

Figure 1. Myocardial velocity vector imaging. The figure shows the VVI with myocardial velocity vectors. The direction of the arrows represents the direction of contraction and the length of the arrow is proportional to myocardial velocity. Top right: Myocardial velocity curves. Bottom right: M-mode representation of dyssynchrony with the red phase representing systole and the blue phase representing diastole.

Figure 2. An example of longitudinal LV dyssynchrony analysis using the velocity vector imaging (VVI) technique. The figure shows a longitudinal VVI analysis. Top left: Myocardial longitudinal velocity vectors are shown. Bottom left: Longitudinal velocity curves for basal septal and basal lateral myocardial walls are shown. Top right: The time to peak longitudinal velocities of the basal septal (base left) and basal lateral (base right) walls are measured in this view. In this analysis, the longitudinal septal to lateral wall delay is $34 \mathrm{~ms}$.

Figure 3. An example of circumferential LV dyssynchrony analysis using the VVI technique. The figure shows the circumferential VVI analysis of an obese subject. Top left: Myocardial circumferential velocity vectors are shown. Bottom left: Circumferential velocity curves for the various myocardial segments seen in the short axis view at the level of the papillary muscles. Top right: The time to peak circumferential velocities of the anterior, anterolateral, infero-lateral, inferior, inferoseptal and antero-septal walls (starting from 12 'O' clock position and proceeding in a clockwise direction) are shown. In this VVI analysis, the max. circumferential wall dyssynchrony is $167 \mathrm{~ms}$.

Figure 4. A bar diagram comparing the mean LVEF and SD of the obese subjects with and without longitudinal septal to lateral (S-L) wall delay of $>75 \mathrm{~ms}$. 
Table 1. Baseline demographic, clinical and laboratory data.

\begin{tabular}{|l|l|l|l|}
\hline Variable & Obese (n=74) & Non-Obese (n=62) & p value \\
\hline Age (in years) & $53 \pm 13$ & $57 \pm 18$ & 0.13 \\
\hline Male & $22(29 \%)$ & $22(35 \%)$ & 0.58 \\
\hline African-Americans & $64(86 \%)$ & $40(65 \%)$ & $<0.01$ \\
\hline Hypertension & $57(77 \%)$ & $39(63 \%)$ & 0.09 \\
\hline Diabetes Mellitus & $26(35 \%)$ & $17(27 \%)$ & 0.36 \\
\hline Hypercholesterolemia & $20(27 \%)$ & $14(23 \%)$ & 0.69 \\
\hline History of TIA or Stroke & $3(4 \%)$ & $3(5 \%)$ & 0.54 \\
\hline Smoker & $18(24 \%)$ & $19(31 \%)$ & 0.44 \\
\hline COPD & $2(3 \%)$ & $4(6 \%)$ & 0.41 \\
\hline Known OSA & $1(1 \%)$ & $3(5 \%)$ & 0.62 \\
\hline On Hemodialysis & $2(3 \%)$ & $4(6 \%)$ & 0.41 \\
\hline Hemoglobin (g/dL) & $11.9 \pm 2.5$ & $12 . \pm 1.7$ & $1.8 \pm 2.7$ \\
\hline Creatinine (mg/dL) & $1.4 \pm 1.4$ & & \\
\hline TIA=transient ischemic attack; OSA=obstructive sleep apnea; & & \\
\hline
\end{tabular}


Table 2. Baseline hemodynamic, echocardiographic and electrocardiographic data

\begin{tabular}{|c|c|c|c|}
\hline Variables & Obese $(n=74)$ & Non-Obese $(n=62)$ & $\mathrm{p}$ value \\
\hline \multicolumn{4}{|l|}{ Hemodynamic Parameters } \\
\hline Heart Rate (beats per minute) & $79 \pm 15$ & $81 \pm 17$ & 0.66 \\
\hline Systolic Blood Pressure (mm of $\mathrm{Hg}$ ) & $141 \pm 22$ & $129 \pm 19$ & $<0.01$ \\
\hline Diastolic Blood Pressure ( $\mathrm{mm}$ of $\mathrm{Hg}$ ) & $79 \pm 12$ & $73 \pm 10$ & $<0.01$ \\
\hline \multicolumn{4}{|l|}{ Echocardiographic Parameters } \\
\hline Ejection fraction $(\%)$ & $60 \pm 7$ & $61 \pm 8$ & 0.22 \\
\hline Pulmonary Artery Systolic Pressure (mm of Hg) & $33 \pm 11$ & $31 \pm 13$ & 0.55 \\
\hline Diastolic Dysfunction* (Grade 1) & $51(69 \%)$ & $33(53 \%)$ & 0.08 \\
\hline Left Atrial Diameter $(\mathrm{cm})$ & $3.5 \pm 0.6$ & $3.4 \pm 0.6$ & 0.48 \\
\hline Left Ventricular Diastolic Dimension $(\mathrm{cm})$ & $4.8 \pm 0.5$ & $4.5 \pm 0.5$ & $<0.01$ \\
\hline Septal Wall Thickness $(\mathrm{cm})$ & $1.1 \pm 0.1$ & $1 \pm 0.2$ & 0.01 \\
\hline Posterior Wall Thickness (cm) & $1.1 \pm 0.2$ & $1 \pm 0.2$ & $<0.01$ \\
\hline Left Ventricular Mass (gms) & $193 \pm 57$ & $155 \pm 56$ & $<0.01$ \\
\hline Left Ventricular Mass Index (LVMI) $\left(\mathrm{gms} / \mathrm{m}^{2}\right)$ & $91 \pm 23$ & $89 \pm 30$ & 0.72 \\
\hline \multicolumn{4}{|l|}{ Electrocardiographic Parameters } \\
\hline QRS Duration (ms) & $85 \pm 10$ & $81 \pm 8$ & $<0.01$ \\
\hline T-Wave Inversions & $13(18 \%)$ & $16(26 \%)$ & 0.29 \\
\hline Left Ventricular Hypertrophy** & $8(11 \%)$ & $5(8 \%)$ & 0.77 \\
\hline Q waves & $1(1 \%)$ & $3(5 \%)$ & 0.32 \\
\hline \multicolumn{4}{|c|}{$\begin{array}{l}* \text { None of the subjects had diastolic dysfunction greater than grade } 1 . \\
* * \text { Based on Sokolow-Lyon or Cornell criteria. } \mathrm{mm}=\text { millimeters; } \mathrm{Hg}=\text { Mercury; cm=centimeters; }\end{array}$} \\
\hline
\end{tabular}


Table 3. Occurrence of dyssynchrony among obese and non-obese subjects

\begin{tabular}{|c|c|c|c|}
\hline Dyssynchrony Parameters & Obese $(n=74)$ & Non-Obese $(n=62)$ & $p$ value \\
\hline \multicolumn{4}{|l|}{ Longitudinal Dyssynchrony } \\
\hline Septal to lateral (S-L) wall delay $>75 \mathrm{~ms}$ & $7(9.4 \%)$ & 0 & 0.01 \\
\hline Anterior to inferior (A-I) wall delay $>75 \mathrm{~ms}$ & $6(8.1 \%)$ & $2(3.2 \%)$ & 0.20 \\
\hline Maximum delay $>100 \mathrm{~ms}$ & $31(41.8 \%)$ & $5(8 \%)$ & $<0.01$ \\
\hline \multicolumn{4}{|l|}{ Longitudinal Strain Dyssynchrony } \\
\hline S-L wall delay $>75 \mathrm{~ms}$ & $23(31 \%)$ & $5(8 \%)$ & $<0.01$ \\
\hline A-I wall delay $>75 \mathrm{~ms}$ & $20(27 \%)$ & $10(16.1 \%)$ & 0.14 \\
\hline Maximum delay $>100 \mathrm{~ms}$ & $43(58.1 \%)$ & $21(33.8 \%)$ & $<0.01$ \\
\hline \multicolumn{4}{|l|}{ Radial Dyssynchrony } \\
\hline S-L wall delay $>75 \mathrm{~ms}$ & $58(78.3 \%)$ & $24(38.7 \%)$ & $<0.01$ \\
\hline A-I wall delay $>75 \mathrm{~ms}$ & $60(81 \%)$ & $12(19.3 \%)$ & $<0.01$ \\
\hline Maximum delay $>100 \mathrm{~ms}$ & $67(90.5 \%)$ & $39(62.9 \%)$ & $<0.01$ \\
\hline \multicolumn{4}{|l|}{ Circumferential Dyssynchrony } \\
\hline Anterior to inferior wall (A-I) delay $>100 \mathrm{~ms}$ & $12(16.2 \%)$ & $1(1.6 \%)$ & $<0.01$ \\
\hline Anterolateral to Inferoseptal (AL-IS) wall delay $>100 \mathrm{~ms}$ & $9(12.1 \%)$ & $1(1.6 \%)$ & 0.02 \\
\hline Inferolateral to Anteroseptal (IL-AS) wall delay $>100 \mathrm{~ms}$ & $12(16.2 \%)$ & 0 & $<0.01$ \\
\hline Maximum Delay $>100 \mathrm{~ms}$ & $20(27 \%)$ & $1(1.6 \%)$ & $<0.01$ \\
\hline \multicolumn{4}{|l|}{ Circumferential Strain Dyssynchrony } \\
\hline A-I wall delay $>100 \mathrm{~ms}$ & $3(4 \%)$ & 0 & 0.25 \\
\hline AL-IS wall delay $>100 \mathrm{~ms}$ & $8(10.8 \%)$ & $1(1.6 \%)$ & 0.03 \\
\hline IL-AS wall delay $>100 \mathrm{~ms}$ & $3(4 \%)$ & 0 & 0.25 \\
\hline Maximum Delay $>100 \mathrm{~ms}$ & $8(10.8 \%)$ & $1(1.6 \%)$ & 0.03 \\
\hline $\mathrm{ms}=$ milliseconds & & & \\
\hline
\end{tabular}


Table 4. Comparison of dyssynchrony parameters between the obese and non-obese subjects using univariate analysis

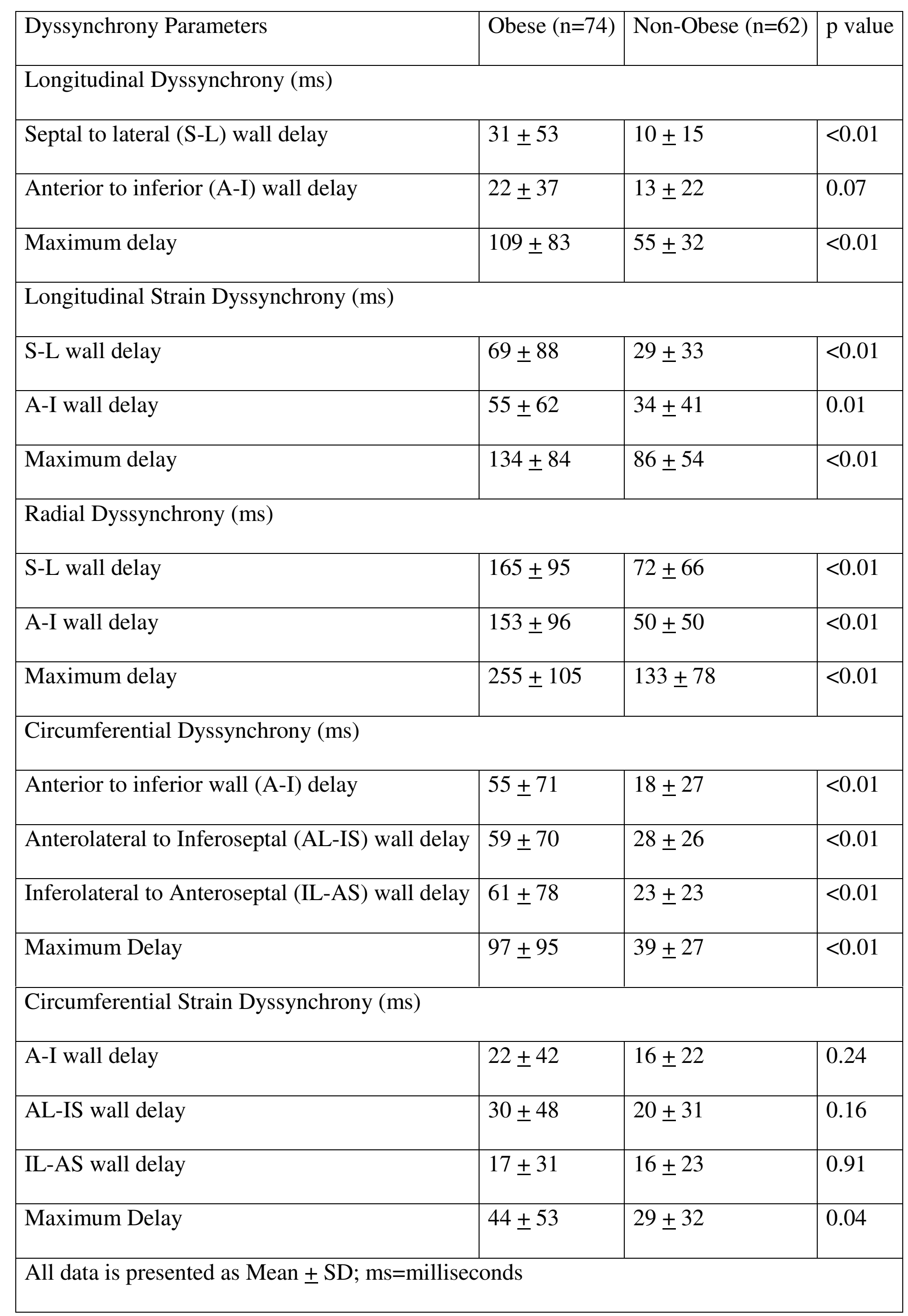


Table 5. Comparison of dyssynchrony parameters between obese and non-obese using multivariate* analysis

\begin{tabular}{|l|l|l|l|}
\hline Dyssynchrony Parameters & Obese (n=74) & Non-Obese (n=62) & $\mathrm{p}$ value \\
\hline Longitudinal S-LWall Delay (ms) & $31 \pm 53$ & $10 \pm 15$ & $<0.01$ \\
\hline Radial S-L Wall Delay (ms) & $165 \pm 95$ & $72 \pm 66$ & $<0.01$ \\
\hline Circumferential Max. Opposing Wall Delay (ms) & $97 \pm 95$ & $39 \pm 27$ & 0.01 \\
\hline Longitudinal Strain S-L Wall Delay (ms) & $69 \pm 88$ & $29 \pm 33$ & $<0.01$ \\
\hline Circumferential Strain Max. Opposing Wall Delay (ms) & $44 \pm 53$ & $29 \pm 32$ & 0.88 \\
\hline *adjusted for age, gender, race, LVEF, diastolic dysfunction, SWT, PWT, LVIDd, QRS duration, LV mass, \\
\hline
\end{tabular}


Table 6. Comparison of dyssynchrony parameters between morbidly obese and obese subjects using univariate analysis

\begin{tabular}{|c|c|c|c|}
\hline Dyssynchrony Parameters & Morbidly Obese $(n=24)$ & Obese $(n=50)$ & $\mathrm{p}$ value \\
\hline \multicolumn{4}{|l|}{ Longitudinal Dyssynchrony (ms) } \\
\hline Septal to lateral (S-L) wall delay & $40 \pm 65$ & $26 \pm 47$ & 0.35 \\
\hline Anterior to inferior (A-I) wall delay & $23 \pm 35$ & $22 \pm 38$ & 0.89 \\
\hline Maximum delay & $125 \pm 98$ & $101 \pm 74$ & 0.29 \\
\hline \multicolumn{4}{|l|}{ Longitudinal Strain Dyssynchrony (ms) } \\
\hline S-L wall delay & $70 \pm 73$ & $68 \pm 95$ & 0.92 \\
\hline A-I wall delay & $69 \pm 60$ & $48 \pm 62$ & 0.18 \\
\hline Maximum delay & $145 \pm 74$ & $129 \pm 89$ & 0.41 \\
\hline \multicolumn{4}{|l|}{ Radial Dyssynchrony (ms) } \\
\hline S-L wall delay & $157 \pm 92$ & $169 \pm 97$ & 0.60 \\
\hline A-I wall delay & $195 \pm 96$ & $134 \pm 91$ & 0.01 \\
\hline Maximum delay & $279 \pm 113$ & $244 \pm 100$ & 0.19 \\
\hline \multicolumn{4}{|l|}{ Circumferential Dyssynchrony (ms) } \\
\hline Anterior to inferior wall (A-I) delay & $51 \pm 59$ & $57 \pm 76$ & 0.69 \\
\hline Anterolateral to Inferoseptal (AL-IS) wall delay & $82 \pm 81$ & $48 \pm 62$ & 0.07 \\
\hline Inferolateral to Anteroseptal (IL-AS) wall delay & $54 \pm 63$ & $64 \pm 84$ & 0.55 \\
\hline Maximum Delay & $94 \pm 87$ & $99 \pm 100$ & 0.84 \\
\hline \multicolumn{4}{|l|}{ Circumferential Strain Dyssynchrony (ms) } \\
\hline A-I wall delay & $36 \pm 63$ & $16 \pm 25$ & 0.14 \\
\hline AL-IS wall delay & $20 \pm 26$ & $34 \pm 55$ & 0.14 \\
\hline IL-AS wall delay & $17 \pm 29$ & $17 \pm 32$ & 0.97 \\
\hline Maximum Delay & $43 \pm 43$ & $45 \pm 58$ & 0.86 \\
\hline \multicolumn{4}{|l|}{ All data presented as Mean $\pm \mathrm{SD} ; \mathrm{ms}=$ milliseconds } \\
\hline
\end{tabular}


Figure 1

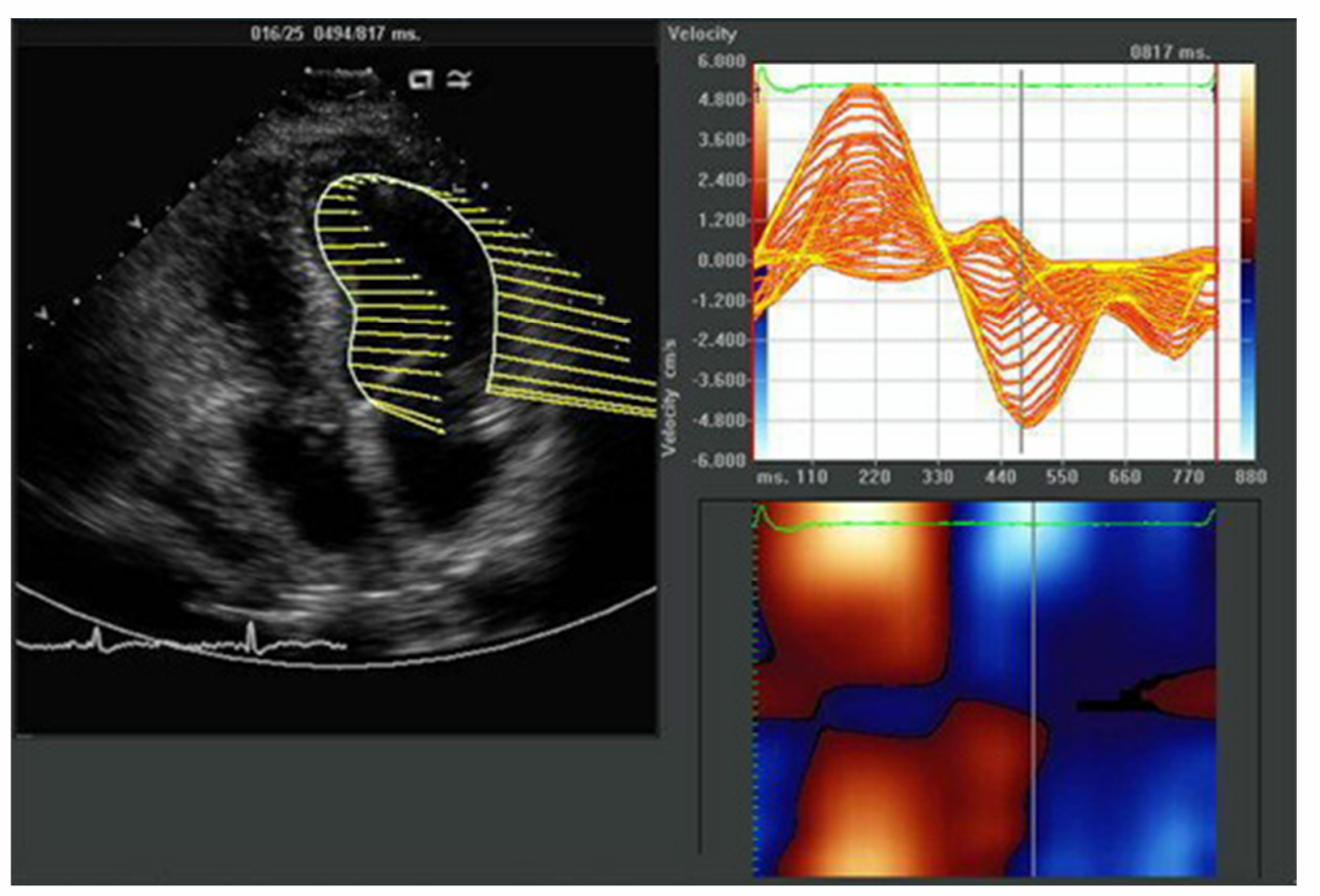


Figure 2 